Kodifikasia : Jurnal Penelitian Islam, Vol 15, No. 01 (2021), 111-131

DOI : 10.21154/kodifikasia.v15i1.2710

ISSN : 1907-6371 (Cetak)

ISSN : 2527-9254 (Online)

\title{
ANALISISPENGARUH ISLAMIC CORPORATE GOVERNANCEMODEL STAKEHOLDERTERHADAP KINERJA BANK UMUM SYARIAH DI INDONESIA DITINJAU DARI MAQASHID SYARIAH INDEKS
}

\author{
Mansur Azis*
}

\begin{abstract}
ABSTRAK:
Tujuan bank syariah adalah untuk mewujudkan keadilan sosial, dan pertumbuhan ekonomi sesuai dengan maqashid syariah. Agar bank syariah dapat mencapai kinerja yang baik berdasarkan pendekatan maqashid syariah dibutuhkan corporate governance yang sesuai dengan karakteristik dan tujuan bank syariah, yaitu Islamic corporate governance model stakeholder. Tujuan penelitian ini adalah untuk menganalisis pengaruh Islamic corporate governance model stakeholder terhadap kinerja Bank Umum Syariah berdasarkan maqashid syariah indeks. Metode penelitian yang digunakan adalah metode penelitian kuantitatif. Tekhnik sampling menggunakan purposive sampling. Sampel dalam penelitian ini adalah Bank Umum Syariah yang terdaftar di Bank Indonesia/Otoritas Jasa Keuangan dari tahun 2013. 2018. Tekhnik pengumpulan data menggunakan dokumentasi dan observasi. Metode analisis menggunakan statistik deskriptif, uji asumsi klasik, analisis regresi berganda, uji t, uji $\mathrm{F}$, dan koefesien determinasi (R2). Hasil penelitian ini 1) Jumlah dewan komisaris berpengaruh terhadap kinerja bank umum syariah berdasarkan maqashid syariah indeks periode 2013-2018 dengan arah positif, 2) Komisaris independen tidak berpengaruh terhadap kinerja bank umum syariah berdasarkan maqashid syariah indeks periode 2013. 2018 , 3) Jumlah dewan pengawas syariah tidak berpengaruh terhadap kinerja bank umum syariah berdasarkan maqashid syariah indeks periode 2013-2018, 4) Jumlah komisaris independen tidak berpengaruh terhadap kinerja bank umum syariah berdasarkan maqashid syariah indeks periode 2013-2018 dengan besarnya pengaruh 9,7\% sedangkan sisanya sebesar 80,3\% dipengaruhi oleh variabel lain di luar model penelitian ini.
\end{abstract}

Kata Kunci: Komisaris; Independen; Pengawas; Maqashid

*Institut Agama Islam Negeri Ponorogo, email : mansur4215@gmail.com 


\begin{abstract}
:
The purpose of sharia banks is to realize social justice, and economic growth in accordance with sharia maqashid. In order for sharia banks to achieve good performance based on sharia maqashid approach, corporate governance is needed in accordance with the characteristics and objectives of sharia banks, namely Islamic corporate governance model of stakeholders. The purpose of this study is to analyze the influence of Islamic corporate governance stakeholder model on the performance of Sharia Commercial Banks based on sharia maqashid index. The research method used is quantitative research method. Sampling techniques using purposive sampling. The sample in this study is Sharia Commercial Bank registered with Bank Indonesia/Otoritas Jasa Keuangan from 2013-2018. Data collection techniques using documentation and observation. The analysis method uses descriptive statistics, classic assumption tests, multiple regression analysis, t-tests, F-tests, and determinant coeffesients (R2). The results of this study 1) The number of board of commissioners affects the performance of sharia commercial banks based on sharia maqashid index period 2013-2018 with a positive direction,2) Independent commissioners have no effect on the performance of sharia commercial banks based on sharia maqashid index period 2013-2018,3) The number of sharia supervisory boards has no effect on the performance of banks sharia general based on sharia maqashid index period 2013-2018,4) The number of independent commissioners has no effect on the performance of sharia commercial banks based on the sharia maqashid index for the period 2013-2018 with a magnitude of 9.7\% while the remaining $80.3 \%$ other variables outside of this research model.
\end{abstract}

Keywords: Commissioner; Independent; Supervisor; Maqashid

\title{
PENDAHULUAN
}

Kehadiran bank syariah semenjak tahun 1991 memberikan alternatif pilihan bagi masyarakat Indonesia yang menginginkan bebas dari bunga dalam bertransaksi dengan perbankan. Sistem perbankan yang ditawarkan oleh bank syariah berbeda dengan bank konvensional, yaitu sistem syariah dalam semua transaksi, produk, dan operasional. Sistem syariah ini berusaha untuk menghilangkan riba, gharar, dan maisir yang dianggap haram oleh umat Islam. Sebagai gantinya adalah menghadirkan sistem bagi hasil, jual-beli, dan sewa-menyewa dalam produk-produk perbankan agar dapat 
memikat hati mayoritas masyarakat muslim di Indonesia untuk bertransaksi dengan perbankan.

Namun dari semenjak awal kehadirannya, bank syariah belum menunjukkan perkembangan yang cukup menggembirakan dari sisi pertumbuhan bisnisnya. Salah satu persolan yang menghambat pertumbuhan bank syariah di Indonesia adalah rendahnya pemahaman dan kesadaran masyarakat terhadap bank syariah. ${ }^{1}$ Sebagai contoh jika dibandingkan indek literasi keuangan syaraiah dan keuangan nasional pada tahun 2016 maka indeks literasi keuangan syariah sektoral perbankan syariah sangat kecil yaitu hanya sebesar 6,63\%, hail ini sangat kecil apabila dibandingkan dengan indeks literasi keuangan nasional sektoral perbankan sebesar 28,94\%. Selain itu indeks inklusi keuangan syariah sektoral perbankan syariah hanya sebesar 9,61\% haliini sangat kesil apa bila dibandingkan dengan indeks inklusi keuangan nasional sektoral perbankanyaitu sebesar $63,63 \% .^{2}$

Rendahnya kesadaran masyarakat Indonesia untuk bertransaksi dengan perbankan syariah bukan disebabkan persoalan tekhnis seperti layanan, jaringan kantor, produk, dan lain-lain, tapi lebih kepada persoalan non tekhnis yaitu kurangnya sosialiasi yang masif bahwa bunga bank konvensional adalah haram dan solusinya sistem syariah, seperti bagi-hasil, jual-beli, dan sewa-menyewa. Selain persoalan tersebut, menurut Abozaid \& Dusuki terdapat persoalan lain, yaitu secara operasional perbankan terdapat kesan bahwa bank syariah dianggap sebagai "old skeleton in modern dress", yaitu terdapat kemiripan praktek bank syariah dengan bank konvensional. Hal ini ditunjukkan dengan banyaknya perbankan Islam baik secara nasional maupun global yang lebih menerapkan pembiayaan berbasis hutang (debt-based instrument) daripada pembiayaan berbasisprofit and loss sharing (equity-based instrument). ${ }^{3}$

Selain persoalan di atas, dari sisi tujuan bank syariah juga terkesan tidak ada perbedaan dengan tujuan bank konvensional. Menurut Mohammad \& Shahwan banyak bank syariah yang terkesan hanya

${ }^{1}$ Dana Aditiasari, "7 Hambatan Yang Buat Bank Syariah Lambat Berkembang Di RI," November 21, 2015, https://finance.detik.com/moneter/d-3076959/7-hambatanyang-buat-bank-syariah-lambat-berkembang-di-ri.

2 "Survei Nasional Literasi dan Inklusi Keuangan 2016," accessed June 2, 2021, https://www.ojk.go.id/id/berita-dan-kegiatan/siaran-pers/Documents

3 Abdulazeem Abozaid and Asyraf Wajdi Dusuki, "The Challenges of Realizing Maqasid Al-Shariah in Islamic Banking and Finance," A Paper Presented at the IIUM International Conference on Islamic Banking and Finance:'Research and Development: The Bridge between Ideals and Realities' Organized by IIUM Institute of Islamic Banking and Finance, April 23, 2007, 1-27. 
berorentasi pada keuntungan. ${ }^{4}$ Padahal selain mencapai keuntungan, bank syariah juga memiliki tanggungjawab untuk mencapai kesejahteraan sosial dan komitmen mewujudkan maqashid syariah yaitu tercapainya keadilan sosial, pemerataan distribusi pendapatan dan kekayaan, dan pertumbuhan ekonomi melalui transaksi ekonomi dan keuangan yang dimotori oleh bank syariah dengan menggunakan akad-akad yang sesuai syariah. ${ }^{5}$

Untuk menilaimaqashidsyariahpada bank syariah sudah sesuai atau belum, maka diperlukan pengukuran dengan pendekatan maqashidsyariah. Karena selama ini pengukuran kinerja bank syariah dilakukan dengan menggunakan rasio-rasio keuangan yang diadaptasi dari pengukuran kinerja bank konvensional, seperti ROA, ROE, ROI, dan lain-lain. ${ }^{6}$ Padahal penggunaan rasio-rasio keuangan tersebut, tidak relevan untuk mengukur kinerja bank syariah, karena bank syariah memiliki tujuan yang lebih luas daripada bank konvensional. Dampaknya, masyarakat tidak dapat melihat secara jelas perbedaan tujuan antara bank syariah dengan bank konvensional. ${ }^{7}$

Untuk mengukur kinerja bank syariah berdasarkan maqashid syariahMohammed, mengembangkan maqashid syariah indeks yang di-break downdari rumusan maqashid syariah Abu Zahrah yang memembagimaqashid syariah menjadi tiga bagian yaitu:pertamaMendidik individu, kedua Menegakkan keadilan, ketiga Memelihara kemasalahatan. dalam membreak down konsep maqahsid syariah Abu Zahrah,Mohammed menggunakan metode Sekaran untuk menjadi indikator-indikator yang memiliki elemenelemen yang kemudian diproksikan dengan rasio-rasio keuangan bank Islam. ${ }^{8}$

Agar kinerja bank syariah tercapai dengan baik berdasarkan pendekatan maqashid syariah di perlukan tata kelola perusahaan (corporate governance) yang sesuai dengan karakteristik dan tujuan bank

${ }^{4}$ Mustafa Omar Mohammad and Syahidawati Shahwan, "The Objective of Islamic Economic and Islamic Banking in Light of Maqasid Al-Shariah: A Critical Review," 2013, 10.

${ }^{5}$ Abozaid and Dusuki, "The Challenges of Realizing Maqasid Al-Shariah in Islamic Banking and Finance," 1-27.

6 Ahmed Mohamed Badreldin, "Measuring the Performance of Islamic Banks by Adapting Conventional Ratios, Working Paper Series 16," Faculty of Management Technology German University in Cairo, 2, Oktober 2009, 1-28.

${ }^{7}$ Mustafa Omar Mohammed and Dzuljastri Abdul Razak, "The Performance Measures of Islamic Bankinng Based on The Maqasid Framework" (the IIUM International Accounting Conference (INTAC IV) held at Putra Jaya Marroitt, Malaysia: Department of Economics, Kulliyyah of Economics and Management Sciences, International Islamic University Malaysia, 2008), 1-17.

${ }^{8}$ Mohammed and Razak. 
syariah, yaitu Islamic corporate governance model stakeholder. ${ }^{9}$ Model ini menekankan pada mekanisme dan struktur governance yang melindungi hak dan kepentinganseluruh stakeholder. ${ }^{10}$ Versi ini merupakan model yang dimodifikasi dari corporate governance Eropa atau stakeholder model yang melindungi kepentingan semua stakeholder pada posisi yang sama. Aturan syariah yang dimodifikasi mengikat semua pemangku kepentingan termasuk pemegang saham, dan manajemen lainnya. ${ }^{11}$

Mekanisme Islamic corporate govenance model stakeholder memiliki struktur governance, seperti: Dewan Komisaris, Direksi, dan Dewan Pengawas Syariah yang memiliki tugas dan tanggungjawab masing-masing. Atas namapemegang saham Dewan Komisaris bertugas mengawasi dan memantau keselurahan kegiatan bisnis. Pengelolaan perusahaan merupakan kewajiban Direksi sebagai bentuk amanah dari seluruh pemangku kepentingan, tidak hanya sebagai pemegang saham. Dewan Pengawas Syariah sebagai fitur yang unik dalam mekanisme Islamiccorporate governance memiliki peran untuk memberikan nasihat dan mengawasi kegiatan operasi perusahaan agar sesuai dengan prinsip-prinsip syariah.

Islamic corporate governance model stakeholder memiliki tugas mengawasi aktivitas direksi dalam mengelola perusahaan diharapkan dapat meningkatkan kinerja bank syariah yang diukur mengunakan maqashid syariah guna tercapainya tujuan bank syariah. Berdasarkan latar belakang masalah di atas, maka analisis tentang Islamic corporate governancemodel stakeholder (jumlah Dewan Komisaris, Komisaris Independen, dan Dewan Pengawas Syariah) untuk meningkatkan efektifitas kepengawasan agar kinerja bank syariah memenuhi maqashid syariah harus dibuktikan melalui penelitian empiris dengan judul: "Analisis Pengaruh Islamic Corporate Governancemodel Stakeholder Terhadap Kinerja Bank Umum Syariah Di Indonesia Ditinjau Dari Maqashid Syariah Indeks".

\section{PEMBAHASAN}

\section{Teori Corporate Governance}

Hung membuat tipologi teori yang berkaitan dengan corporate governance terutama bagaimana peran dewan komisaris (board of directors) dalam pengambilan keputusan agar dapat meningkatkan kinerja perusahaan. Berdasarkan perspektif pengaruh ekstrinsik (Extrinsic Influence Perspective)

${ }^{9}$ Zulkifli Hasan, "Corporate Governance: Western and Islamic Perspecitves," International Review of Business Research Papers, 1, 5 (January 1, 2009): 277-93.

${ }^{10}$ Zamir Iqbal and Abbas Mirakhor, "stakeholders Model of Governance In Islamic Economic System," Islamic Economic Studies 11, no. 2 (n.d.): 22.

${ }^{11}$ M. Umer Chapra and Habib Ahmed, Corporate Governance Lembaga Keuangan Syariah, (Terj) Ikhwan Abidin Basri (Jakarta: Bumi Aksara, 2008), 18-19. 
atau perpektif contingency (contingency perspective) bahwaperan dan fungsi komisaris (board) dalam pengambilan keputusan dipengaruhi oleh faktor lingkungan perusahaan dimanamereka bekerja, yaitu faktor eksternal dan internal perusahaan. ${ }^{12}$ Baik faktor eksternal maupun internal memiliki teori yang dapat menjelaskan bagaimana peran dan fungsi komisaris.

Adanya tuntutan lingkungan eksternal terhadap perusahaan memaksa komisaris (board) menjalankan fungsi dan perannya dalammelakukan koordinasi (coordinating role) dengan pihak-pihak lingkungan bisnis eksternal. Untuk memahami bagaimana komisaris (board) menjalankan fungsi koordinasi (coordinating role), menurut Hung harus menggunakan stakeholder theory yang dikembangkan oleh Freeman. Menurut stakeholder theory, stakeholder adalah pihak individu atau kelompok yang berpengaruh atau terpengaruh pada pencapaian tujuan perusahaan. Oleh karena itu peran komisaris (board) diharapkan dapat berkompromi dan bernegoisasi dengan stakeholder demi kepentingan perusahaan. ${ }^{13}$ Agar fungsi dan peran komisaris (board) dapat berjalan efektif dan meningkatan kinerja perusahaan, menurut stakeholder theory semakin banyak dan bervariasi orang yang duduk dalam jajaran komisaris (board) akanberdampak pada kemampuan dalam mengakomodasi dan memfasilitasi kepentingan setiap pihak untuk menciptakan nilai tambah bagi perusahaan. ${ }^{14}$

Adanya tekanan lingkungan internal terhadap kinerja perusahaan memaksa komisaris (board) menjalankan perannya sebagai pengawas (control role) terhadap lingkungan bisnis internal. Peran komisaris sebagai pengawas dapat dijelaskan melalui agency theory yang dikembangkan oleh Jensen \& Meckling. Menurut agency theory, mekanisme dapat membatasi seorang agen bertindak untuk kepentingan pribadi dalam situasi dimana pihak prinsipal dan agen memiliki konflik atau perbedaan tujuan masing-

${ }^{12}$ Humphry Hung, "A Typology of the Theories of the Roles of Governing Boards," Corporate Governance: An International Review 6, no. 2 (April 1998): 101-111, https:// doi.org/10.1111/1467-8683.00089.

${ }^{13}$ Hung, 106.

${ }^{14}$ Bello Lawal, "Board Dynamics and Corporate Performance: Review of Literature, and Empirical Challenges," International Journal of Economics and Finance 4, no. 1 (December 14, 2011): p22, https://doi.org/10.5539/ijef.v4n1p22.composition, CEO Duality and Diversity amongst others. While the need to assess the connection between board characteristics and corporate performance would for a longtime remained a legitimate and interesting area of investigation, the paper recommend that the researchers avoid mistakes of the past. These include over reliance on singular theory, the use of lone performance measure and most importantly the assumption of express relationship between the two variables. The use of more purposeful process based approach that identifies the cause effect of the relationship would be of tremendous benefit to this vital field of study.","containertitle":"International Journal of Economics and Finance","DOI":"10.5539/ijef. v4n1p22","ISSN":"1916-9728, 1916-971X","issue":"1","journalAbbreviation":"IJEF","lan guage":"en","page":"p22","source":"DOI.org (Crossref

Kodifikasia: Jurnal Penelitian Islam, Volume, 15 No. 1 Tahun 2021 
masing. ${ }^{15}$ Dalam hal ini, komisaris diharapkan dapat mengurangi perilaku opportunis agen melalui penambahan jumlah komisaris independen dipercaya dapat mengurangi perilaku manajemen bertindak manipulasi dan dapat meredam konflik kepentingan antara pihak prinsipal dan agen. ${ }^{16}$

Sedangkan untuk menjelaskan peran Dewan Pengawas Syariah dalam meningkatkan kinerja bank syariah, Nopica, dkk mengusulkan teori akuntabilitas Islam (Islamic accountability theory). ${ }^{17}$ Akuntabilitas dalam Islam menurut El-Halaby memiliki konotasi dengan amanah. Akuntabilitas yang paling utama adalah akuntabilitas kepada Allah yang berarti beribadah kepada-Nya dan tunduk patuh terhadap perintah-Nya dengan menjalankan aturan syariah dalam kehidupan. El-Halaby mengembangkan teori akuntabilitas Islam berdasarkan survey terhadap ayat-ayat Al-Quran yang berkaitan dengan akuntabilitas dengan kesimpulan bahwa terdapat 3 (tiga) pilar akuntabilitas menurut perspektif Islam, yaitu: akuntabilitas syariah, akuntabilitas sosial, dan akuntabilitas finansial. ${ }^{18}$

Akuntabilitas syariah merupakan bentuk pertanggungjawaban kepada Allah melalui implementasi ketaatan dan kepatuhan terhadap aturan syariah sebagai pedoman kehidupan. Dalam konteks Islamic corporate governance, tanggungjawab pemeliharaan bank Islam agar patuh terhadap syariah dipegang oleh Dewan Pengawas Syariah yang memiliki peran antara lain: 1) Memberikan nasehat/saran kepada Dewan Komisaris/Direksi tentang kesesuaian transaksi bisnis dengan aturan syariah, 2) Membuat laporan secara berkala kepada pemegang saham tentang kepatuhan manajemen terhadap prinsip-prinsip syariah, 3) Menghitung kewajiban zakat perusahaan. ${ }^{19}$

Akuntabilitas sosial merupakan bentuk pertanggungjawaban kepada sosial melalui implementasi program-program kepedulian sosial yang

${ }^{15}$ Hung, "A Typology of the Theories of the Roles of Governing Boards," 106.

${ }^{16}$ Lawal, "Board Dynamics and Corporate Performance," 23.composition, CEO Duality and Diversity amongst others. While the need to assess the connection between board characteristics and corporate performance would for a longtime remained a legitimate and interesting area of investigation, the paper recommend that the researchers avoid mistakes of the past. These include over reliance on singular theory, the use of lone performance measure and most importantly the assumption of express relationship between the two variables. The use of more purposeful process based approach that identifies the cause effect of the relationship would be of tremendous benefit to this vital field of study.","container-title":"International Journal of Economics and Finance","DOI":"10.5539/ijef.v4n1p22","ISSN":"1916-9728, 1916-971X","issue":"1","jo urnalAbbreviation":"IJEF","language":"en","page":"p22","source":"DOI.org (Crossref

${ }^{17}$ Ince Nopica et al., "The Basic Theory of Corporate Governance in Islamic Perspective," Media Syari'ah 18, no. 2 (2016): 69-79.

${ }^{18}$ Sherif Ismail Abdel-Rahman El-Halaby, "Accountability Practices of Islamic Banks:

A Stakeholders' Perspective," n.d., 60-74.

${ }^{19}$ El-Halaby, 60-74. 


\section{8 | Mansur Azis}

dilakukan oleh perusahaan Islam berlandaskan tauhid. Contoh bentuk program kepedulian sosial, adalah CSR atau zakat. ${ }^{20}$ Dewan Pengawas Syariah berperan penting dalam menghitung kewajiban zakat perusahaan dan memberikan saran dan nasehat kepada Dewan Komisaris dan direksi tentang orang-orang yang berhak menerima zakat tersebut. Akuntabilitas finansial merupakan bentuk pertanggungjawaban finansial melalui laporan keuangan yang diterbitkan oleh perusahaan Islam yang ditujukan kepada stakeholder sebagai sinyal keberhasilan manajemen dalam mengelola amanah menjalankan bisnis. ${ }^{21}$ Dewan Pengawas Syariah memiliki peran dalam hal memberikan saran dan nasehat kepada Dewan Komisaris dan direksi dalam menghitung distribusi bagi hasil yang ditujukan kepada para nasabah pemegang rekening simpanan dana syirkah temporer.

Maka, menurut teori akuntabilitas Islam (Islamic accountability theory) adanya peningkatan jumlah Dewan Pengawas Syariah dapat meningkatkan kualitas 3 (tiga) pilar akuntabilitas, yaitu: syariah, sosial, dan finansial. Artinya dewan pengawas syariah memiliki peran akuntabilitas (accountability role) dalam hal pertanggungjawaban kepada Allah melalui penjagaan operasional bank syariah sesuai dengan syariah, pertanggungjawaban sosial melalui distribusi zakat, dan pertanggungjawaban finansial dengan cara melindungi hak dan kepentingan para pemilik akun simpanan dana syirkah temporer. ${ }^{22}$

\section{Hasil Uji Statistik}

Hasil uji statistik pengaruh jumlah dewan komisaris, jumlah komisaris independen, dan jumlah dewan pengawas syariah terhadap kinerja bank umum syariah berdasarkan maqashid syariah indeks periode 2013-2018 sebagai berikut:

Tabel. Rekapitulasi Hasil Pengujian Statistik

\begin{tabular}{|l|l|l|l|}
\hline \multicolumn{1}{|c|}{ Hipotesis } & \multicolumn{1}{c|}{ Uji Regresi } & \multicolumn{1}{c|}{ Uji T } & \multicolumn{1}{c|}{ Keterangan } \\
\hline Pengaruh & Koefisien regresi & Variabel jumlah & Jumlah komisaris \\
jumlah komisaris & variabel jumlah & komisaris & independen tidak \\
independen & komisaris & independen & berpengaruh \\
terhadap & independen & memiliki nilai -t & terhadap \\
kinerja bank & sebesar $-0,002$ & hitung sebesar & kinerja bank \\
umum syariah & yang artinya & $-0,139<-t$ tabel & umum syariah \\
berdasarkan & terjadi hubungan & sebesar -2,004 & berdasarkan \\
maqashid syariah & negatif antara & dengan nilai & maqashid \\
\hline
\end{tabular}

${ }^{20}$ El-Halaby, 60-74.

${ }^{21}$ El-Halaby, 60-74.

${ }^{22}$ El-Halaby, 60-74.

Kodifikasia: Jurnal Penelitian Islam, Volume, 15 No. 1 Tahun 2021 


\begin{tabular}{|c|c|c|c|}
\hline Hipotesis & Uji Regresi & Uji T & Keterangan \\
\hline $\begin{array}{l}\text { indeks periode } \\
2013-2018\end{array}$ & \begin{tabular}{|l} 
jumlah komisaris \\
independen dengan \\
kinerja bank umum \\
syariah berdasarkan \\
maqashid syariah indeks. \\
Semakin banyak jumlah \\
anggota komisaris \\
independen maka \\
semakin rendah kinerja \\
bank umum syariah \\
berdasarkan maqashid \\
syariah indeks. \\
\end{tabular} & $\begin{array}{l}\text { signifikan 0,890 } \\
>0,05 \text { maka } \mathrm{H} 02 \\
\text { diterima dan } \mathrm{Ha2} \\
\text { ditolak }\end{array}$ & syariah indeks \\
\hline $\begin{array}{l}\text { Pengaruh } \\
\text { jumlah dewan } \\
\text { pengawas } \\
\text { syariah } \\
\text { terhadap } \\
\text { kinerja bank } \\
\text { umum syariah } \\
\text { berdasarkan } \\
\text { maqashid } \\
\text { syariah indeks } \\
\end{array}$ & \begin{tabular}{|l|} 
Koefisien regresi \\
variabel jumlah \\
dewan pengawas \\
syariah sebesar 0,007 \\
yang artinya terjadi \\
hubungan positif antara \\
jumlah dewan pengawas \\
syariah dengan kinerja \\
bank umum syariah \\
berdasarkan maqashid \\
\end{tabular} & \begin{tabular}{|l|} 
Variabel jumlah \\
dewan pengawas \\
syariah memiliki \\
nilai t hitung sebesar \\
$0,497<\mathrm{t}$ tabel \\
sebesar 2,004 dengan \\
nilai signifikan 0,621 \\
$>0,05$ maka H03 \\
diterima dan Ha3 \\
ditolak \\
\end{tabular} & $\begin{array}{l}\text { Jumlah dewan } \\
\text { pengawas } \\
\text { syariah tidak } \\
\text { berpengaruh } \\
\text { terhadap } \\
\text { kinerja bank } \\
\text { umum syariah } \\
\text { berdasarkan } \\
\text { maqashid } \\
\text { syariah indeks } \\
\end{array}$ \\
\hline & $\begin{array}{l}\text { syariah indeks. Semakin } \\
\text { sedikit jumlah anggota } \\
\text { dewan pengawas syariah } \\
\text { maka semakin rendah } \\
\text { kinerja bank umum } \\
\text { syariah berdasarkan } \\
\text { maqashid syariah } \\
\text { indeks. } \\
\end{array}$ & & \\
\hline \begin{tabular}{|l} 
Pengaruh \\
jumlah dewan \\
komisaris, \\
jumlah \\
komisaris \\
independen, \\
dan jumlah \\
dewan \\
pengawas \\
syariah \\
terhadap \\
kinerja bank \\
umum syariah \\
berdasarkan \\
maqashid \\
syariah indeks
\end{tabular} & \multicolumn{3}{|c|}{$\begin{array}{l}\text { Nilai F hitung sebesar 4,076 > F tabel sebesar 2,79 dan nilai } \\
\text { signifikan 0,011 < 0,05 maka Ho4 ditolak dan Ha4 diterima. } \\
\text { Artinya jumlah dewan komisaris, komisaris independen, dan } \\
\text { dewan pengawas syariah berpengaruh signifikan terhadap } \\
\text { kinerja bank umum syariah berdasarkan maqashid syariah } \\
\text { indeks. }\end{array}$} \\
\hline
\end{tabular}




\begin{tabular}{|c|c|c|c|}
\hline Hipotesis & Uji Regresi & Uji T & Keterangan \\
\hline $\begin{array}{l}\text { periode } 2013 \\
2018\end{array}$ & & & \\
\hline $\begin{array}{l}\text { Koefisien } \\
\text { determinasi } \\
\text { (R2) }\end{array}$ & \multicolumn{3}{|c|}{$\begin{array}{l}\text { Nilai R square 0,197 yang menunjukkan bahwa jumlah dewan } \\
\text { komisaris, jumlah komisaris independen, dan jumlah dewan } \\
\text { pengawas syariah mampu mempengaruhi sebesar } 19,7 \% \\
\text { variasi kinerja bank umum syariah berdasarkan maqashid } \\
\text { syariah indeks periode 2013-2018 dan sisanya sebesar 80,3\% } \\
\text { dipengaruhi oleh variabel lain di luar model penelitian ini }\end{array}$} \\
\hline
\end{tabular}

\section{Pengaruh Jumlah Dewan Komisaris terhadap Kinerja Bank Syariah Berdasarkan Maqashid Syariah Indeks}

Hasil analisisyregresi variabel jumlah dewan komisaris memiliki koefisien regresi bernilaiypositif sebesar 0,020.yArtinya kinerja bank umum syariah akan semakin baik apa bila banyak orang yang duduk dalam jajaran dewan komisaris berdasarkan maqashid syariah indeks periode 2013. 2018. Sedangkan hasilyuji hipotesis variabel jumlah dewan komisaris menghasilkan nilai t hitung $>\mathrm{t}$ tabel atau 2,521 $>2,004$ dengan nilai signifikansi 0,015<0,05.ySehingga dapat disimpulkanybahwa Ho1 ditolak dan Ha1 diterima.yHasil tersebut menunjukkanybahwa kinerja bank umum syariah dipengaruhi oleh jumlah dewan komisaris berdasarkan maqashid syariah indeks.

Bank umum syariah di pengaruhi oleh jumlah dewan komisaris berdasarkan maqashid syariah indeks karena terlihat dari adanya hasil yang selaras pada arah pergerakan data jumlah dewan komisaris dengan data kinerja bank umum syariah berdasarkan maqashid syariah indeks. Berdasarkan data total rata-rata jumlah dewan komisaris bank umum syariah selama periode 2013-2018 pada tabel 4.30 mengalami penurunan. Kondisi ini disebabkan karena terdapat beberapa bank umum syariah yang mengurangi jumlah anggota dewan komisaris yang bertugas mengawasi pengelolaan dan pengawasan kegiatan operasional yang dilakukan oleh bank umum syariah sehingga menyebabkan kinerja bank umum syariah berdasarkan maqashid syariah indeks mengalami penurunan. Hal ini dibuktikan dengan data total rata-rata kinerja bank umum syariah berdasarkan maqashid syariah indeks selama periode 2013-2018 pada tabel 4.36 cenderung mengalami penurunan.

Sebagai contoh, pada tabel 4.30 menunjukkan terdapat beberapa bank umum syariah yang jumlah orang-orang yang duduk dalam jajaran dewan komisaris selama tahun 2013-2018, seperti: Bank Muamalat dan BRI Syariah, artinya kedua bank umum syariah tersebut melakukan pengurangan jumlah orang yang bertugas mengawasi dan mengontrol kinerja manajemen

Kodifikasia: Jurnal Penelitian Islam, Volume, 15 No. 1 Tahun 2021 
sehingga berdampak pada rendahnya kinerja bank umum syariah tersebut berdasarkan maqashid syariah indeks, hal ini dibuktikan dengan kinerja bank umum syariah tersebut berdasarkan maqashid syariah indeks pada tabel 4.36 secara rata-rata cenderung mengalami penurunan selama periode penelitianyang ditunjukkan oleh grafik di bawah ini:

Diterimanya hipotesis yang pertama dalam penelitian ini menunjukkan bahwa banyak dan sedikitnya jumlah dewan komisaris berpengaruh terhadap kinerja bank umum syariah berdasarkan maqashid syariah indeks. Karena dewan komisaris merupakan bagian dari struktur tata kelola (governance structure) bank syariah yang memiliki fungsi pengawasan terhadap pihak eksekutif manajemen dalam pengelolaan bank syariah sehingga stakeholder bank dapat mengharapkan hasil darioutcome yang sesuai. Selain itu,fungsi utama dewan komisaris dalam manajemen, yaitu menetapkan tujuan stratejik dan prinsip-prinsip yang akan dijadikan sebagai acuan operasional bank dan berperan dalam menetapkan kode etik bagi direksi dan standar operasional yang akan menjadi budaya kerja perusahaan. ${ }^{23}$

Menurut perspektif stakeholder theory banyaknya jumlah orang yang duduk dalam jajaran dewan komisaris akan berdampak pada peningkatan kemampuan dalam mengakomodasi dan memfasilitasi kepentingan setiap pihak untuk menciptakan nilai tambah bagi perusahaan. Dewan komisaris mungkin tidak dapat menjalankan semua tugas tersebut secara efektif, jika hanya mengedepankan kepentingan diri sendiri dan mengabaikan kepentingan stakeholders bank termasuk pemegang saham, deposan, karyawan atau pihak lain yang berkepentingan. ${ }^{24}$ Maka diperlukan jumlah dewan komisaris yang banyak untuk dapat lebih memaksimalkan kinerja bank umum syariah yang sesuai dengan maqashid syariah, yaitu: mendidik individu, menegakkan keadilan, dan memilihara kemaslahatan.

Berdasarkan hasil penelitian ini dan berdasarkan perspektif stakeholder theory adanya pengurangan jumlah orang yang duduk dalam jajaran dewan komisaris akan meningkatkan self interest masing-masing anggota dewan komisaris yang sedikti dan tidak memperdulikan kepentingan stakeholder dalam hal mengarahkan manajemen untuk mencapai tujuan bank syariah bukan hanya sekedar mencari keuntungan yang memuaskan pemegang saham tapi juga ditujukan untuk mencapai maqashid syariah melalui mendidik individu, menegakkan keadilan, dan memelihara kemaslahatan.

Hasil penelitian ini mendukung penelitian Quttainah menganalisis pengaruh jumlah dewan komisaris di 15 negara selama periode 1993-2010

${ }^{23}$ Chapra and Ahmed, Corporate Governance Lembaga Keuangan Syariah, (Terj) Ikhwan Abidin Basri, 41-42.

${ }^{24}$ Chapra and Ahmed, 41-42. 


\section{2 | Mansur Azis}

terhadap kinerja 34 bank syariah, menunjukkan bahwa kinerja bank syariah dipengaruhi secara positif signifikan oleh jumlah dewan komisaris yang diukur dengan pertumbuhan asset, ROA, dan ROE. ${ }^{25}$ Penelitian ini relevan dan sejalan dengan hasil penelitianMatousi \& Grassapada pengujian sampel agregrat bank Islam di kawasan Teluk dan Asia Tenggara didapatkan bahwa jumlah dewan komisaris berpengaruh positif terhadap ROA. ${ }^{26}$

\section{Pengaruh Jumlah Komisaris Independen terhadap Kinerja Bank Syariah Berdasarkan Maqashid Syariah Indeks}

Hasil analisisyregresijumlah komisaris independen memiliki koefisien regresi bernilaiynegatif sebesar -0,002.yArtinya berdasarkan maqashid syariah indeks, kinerja bank umum syariah periode 2013-2018 jika semakin sedikit orang yang duduk dalam jajaran komisaris independen maka semakin baik. Sedangkan hasilyuji hipotesis variabel jumlah komisaris independen menghasilkan nilai - t hitung $<-t$ tabel atau $-0,139>-2,004$ dengan nilai signifikansi 0,890 > 0,05.ySehingga dapat disimpulkanybahwa Ho2 ditolak dan Ha2 diterima.yHasil tersebut menunjukkanybahwa berdasarkan maqashid syariah indekskinerja bank umum syariah tidak dipengaruhi oleh jumlah komisaris independen

Berdasarkan maqashid syariah indekskinerja bank umum syariah tidak dapat dipengaruhi oleh Jumlah komisaris independen karena berdasarkan hasil pengumpulan data terlihat beberapa bank umum syariah memiliki pergerakan data jumlah komisaris independen pada tabel 4.31 dan data kinerja bank umum syariah pada tabel 4.36 yang tidak konsistenberdasarkan maqashid syariah indeks, yaitu pergerakan data yang searah dan tidak searah. Bank umum syariah yang memiliki pergerakan data jumlah komisaris independen dan data kinerja bank umum syariah berdasarkan maqashid syariah indeks yang searah adalah bank-bank syariah yang memiliki kecenderungan pada saat ada pengurangan jumlah komisaris independen diiringi dengan turunnya kinerja bank umum syariah berdasarkan maqashid syariah indeks, begitu juga sebaliknya. Sedangkan bank umum syariah yang memiliki pergerakan data jumlah komisaris independen dan data kinerja bank umum syariah berdasarkan maqashid syariah indeks yang tidak searah adalah bank-bank syariah yang memiliki kecenderungan pada saat jumlah

${ }^{25}$ Majdi Anwar Quttainah, "Four Essays on the Impact of Shari'ah (Islamic Law) as an Institutional Governance Mechanism on Organizational Performance and Managerial Behavior," n.d., 1-70.

${ }^{26}$ Hamadi Matoussi and Rihab Grassa, "Is Corporate Governance Different For Islamic Banks? A Comparative Analysis Between The Gulf Cooperation Council Context and The Southeast Asia Context," n.d., 1-28.

Kodifikasia: Jurnal Penelitian Islam, Volume, 15 No. 1 Tahun 2021 
komisaris independennya bertambah tetapi kinerja bank umum syariah berdasarkan maqashid syariah indeksnya turun, demikian pula sebaliknya.

Contoh bank-bank syariah yang memiliki pergerakan data searah adalah Bank Muamalat dan BRI Syariah. Kedua bank syariah tersebut memiliki data jumlah komisaris independen yang cenderung mengalami penurunan juga diikuti dengan data kinerja bank umum syariah berdasarkan maqashid syariah indeks yang cenderung menurun selama periode penelitian yang ditunjukkan oleh grafik di bawah ini:

Sedangkan bank-bank syariah yang memiliki pergerakan data tidak searah adalah Bank Mega Syariah dan BNI Syariah. Kedua bank syariah tersebut memiliki data jumlah komisaris independen yang cenderung mengalami penurunan namun data kinerja bank umum syariah berdasarkan maqashid syariah indeksnya cenderung mengalami peningkatan selama periode penelitian yang ditunjukkan oleh grafik di bawah ini:

Adanya kelompok bank syariah yang pada saat jumlah komisaris independennya berkurang tetapi kinerja bank umum syariah berdasarkan maqashid syariah indeksnya meningkat dan ada juga kolompok bank syariah pada saat jumlah komisaris independennya berkurang tetapi kinerja bank umum syariah berdasarkan maqashid syariah indeksnya juga turun menunjukkan bahwa bertambahnya atau berkurangnya jumlah komisaris independen tidak selamanya dapat menyebabkan tinggi atau rendahnya kinerja bank umum syariah berdasarkan maqashid syariah indeks.

Ditolaknya hipotesis yang kedua dalam penelitian ini menunjukkan bahwa jumlah komisaris independen tidak selalu berpengaruh terhadap kinerja bank umum syariah berdasarkan maqashid syariah indeks. Karena dewan komisaris merupakan pihak yang mewakili pemegang saham dalam sistem pemisahan kepemilikan dan pengawasan di perusahaan modern. Oleh karena itu, pemegang saham akan menempatkan perwakilan dari mereka terutama pemegang saham mayoritas sebagai dewan komisaris untuk melindungi kepentingan pemegang saham. Sedangkan untuk melindungi kepentingan pemegang saham minoritas, maka terdapat Komisaris Independen yang bertindak sebagai anggota dewan Komisaris yang tidak memiliki hubungan apapun dengan anggota dewan Komisaris lainnya, Direksi dan/atau pemegang saham pengendali atau hubungan lain yang dapat mempengaruhi kemampuannya untuk bertindak independen.

Keberadaan komisaris independen dapat memberikan pengawasan yang objektif dan tidak memiliki konflik kepentingan sehingga nasihat dan arahannya lebih pada terwujudnya kinerja bank syariah yang lebih baik. Berdasarkan perspektif agency theory, mekanisme corporate governance dapat membatasi seorang agen bertindak untuk kepentingan pribadi dalam 
situasi dimana pihak prinsipal dan agen memiliki konflik atau perbedaan tujuan masing-masing. ${ }^{27}$ Dalam hal ini, komisaris independen diharapkan dapat mengurangi perilaku opportunis agen melalui banyaknya jumlah komisaris independen dipercaya dapat mengurangi perilaku manajemen bertindak manipulasi dan dapat meredam konflik kepentingan antara pihak prinsipal dan agen agar memperhatikan kepentingan stakeholder, yaitu pertama, mendidik individu, kedua, menegakkan keadilan, ketiga, memelihara kemaslahatan..$^{28}$

Terkait dengan banyak atau sedikitnya jumlah komisaris independen yang dapat melakukan pengawasan terhadap pihak manajemen secara efektif terdapat hasil penelitian yang bervariasi.Penelitian Maurya, dkk, menganalisis hubungan antara komposisi komisaris independen dengan kinerja 12 bank Islam di negara-negara yang tergabung dalam GCC. Hasil penelitian menunjukkan bahwa terdapat hubungan positif antara komposisi komisaris independen dengan kinerja bank Islam yang diukur dengan ROA. ${ }^{29}$ Artinya semakin banyak jumlah komisaris independen maka semakin baik kinerja bank.

Sedangkan studi yang dilakukan oleh Mollah \& Zaman mendapatkan hasil sebaliknya yang menganalisis pengaruh komisaris independen dengan kinerja 86 bank syariah di 25 negara mendapatkan temuan terdapat pengaruh negatif signifikan proporsi dewan komisaris independen terhadap kinerja bank Islam yang diukur dengan kinerja akuntansi yaitu: efesiensi operasi dan return terhadap rata-rata aset bank Islam. ${ }^{30}$ Artinya semakin banyak jumlah komisaris independen maka semakin buruk kinerja bank. Berdasarkan temuan penelitian ini, teori, dan hasil penelitian terdahulu

${ }^{27}$ Hung, "A Typology of the Theories of the Roles of Governing Boards," 106.

${ }^{28}$ Lawal, "Board Dynamics and Corporate Performance," 23.composition, CEO Duality and Diversity amongst others. While the need to assess the connection between board characteristics and corporate performance would for a longtime remained a legitimate and interesting area of investigation, the paper recommend that the researchers avoid mistakes of the past. These include over reliance on singular theory, the use of lone performance measure and most importantly the assumption of express relationship between the two variables. The use of more purposeful process based approach that identifies the cause effect of the relationship would be of tremendous benefit to this vital field of study.","container-title":"International Journal of Economics and Finance","DOI":"10.5539/ijef.v4n1p22","ISSN":"1916-9728, 1916-971X","issue":"1","jo urnalAbbreviation":"IJEF","language":"en","page":"p22","source”:"DOI.org (Crossref

${ }^{29}$ Vishwa Nath Maurya et al., "Correlation Analysis between the Corporate Governance and Financial Performance of Banking Sectors Using Parameter Estimation," American Journal of Theoretical and Applied Statistics, n.d., 27-32.

${ }^{30}$ Sabur Mollah and Mahbub Zaman, "Shari'ah Supervision, Corporate Governance and Performance: Conventional vs. Islamic Banks," Journal of Banking \& Finance 58 (September 2015): 3-39, https://doi.org/10.1016/j.jbankfin.2015.04.030.

Kodifikasia: Jurnal Penelitian Islam, Volume, 15 No. 1 Tahun 2021 
dapat disimpulkan bahwa kinerja bank umum syariah berdasarkan maqashid syariah indeks tidak di pengaruhi oleh jumlah komisaris independen.

\section{Pengaruh Jumlah Dewan Pengawas Syariah terhadap Kinerja Bank Syariah Berdasarkan Maqashid Syariah Indeks}

Hasil analisisyregresi variabel jumlah dewan pengawas syariah memiliki koefisien regresi bernilaiypositif sebesar 0,007.yArtinya semakin sedikit orang yang duduk dalam jajaran dewan pengawas syariah maka semakin rendah kinerja bank umum syariah berdasarkan maqashid syariah indeks periode 2013-2018. Sedangkan hasilyuji hipotesis variabel jumlah dewan pengawas syariah menghasilkan nilai t hitung $<$ t tabel atau 0,497 $<2,004$ dengan nilai signifikansi 0,621 >0,05.ySehingga dapat disimpulkanybahwa Ho3 ditolak dan Ha3 diterima.yHasil tersebut menunjukkanybahwa kinerja bank umum syariah berdasarkan maqashid syariah indeks di pengaruhi oleh jumlah dewan pengawas syariah.

Kinerja bank umum syariah berdasarkan maqashid syariah indeks di pengaruhi oleh jumlah dewan pengawas syariahkarena berdasarkan hasil pengumpulan data terlihat beberapa bank umum syariah memiliki pergerakan data jumlah dewan pengawas syariah pada tabel 4.32 dan data kinerja bank umum syariah berdasarkan maqashid syariah indeks pada tabel 4.36 yang tidak konsisten, yaitu pergerakan data yang searah dan tidak searah. Bank umum syariah yang memiliki pergerakan data kinerja bank umum syariah berdasarkan maqashid syariah indeksdan data jumlah dewan pengawas syariahyang searah adalah bank-bank syariah yang memiliki kecenderungan pada saat ada pengurangan jumlah dewan pengawas syariah diiringi dengan turunnya kinerja bank umum syariah berdasarkan maqashid syariah indeks, begitu juga sebaliknya. Sedangkan bank umum syariah yang memiliki pergerakan data kinerja bank umum syariah berdasarkan maqashid syariah dan data indeks jumlah dewan pengawas syariahyang tidak searah adalah bank-bank syariah yang memiliki kecenderungan pada saat jumlah dewan pengawas syariahnya bertambah tetapi kinerja bank umum syariah berdasarkan maqashid syariah indeksnya turun, demikian pula sebaliknya.

Contoh bank-bank syariah yang memiliki pergerakan data searah adalah Bank Muamalat dan BRI Syariah. Kedua bank syariah tersebut memiliki data jumlah dewan pengawas syariah yang cenderung mengalami penurunan juga diikuti dengan data kinerja bank umum syariah berdasarkan maqashid syariah indeks yang cenderung menurun selama periode penelitian yang ditunjukkan oleh grafik di bawah ini:

Sedangkan bank-bank syariah yang memiliki pergerakan data tidak searah adalah Bank Mega Syariah dan BNI Syariah. Kedua bank syariah 


\section{6 | Mansur Azis}

tersebut memiliki data jumlah dewan pengawas syariah yang cenderung mengalami penurunan namun data kinerja bank umum syariah berdasarkan maqashid syariah indeksnya cenderung mengalami peningkatan selama periode penelitian yang ditunjukkan oleh grafik di bawah ini:

Adanya kelompok bank syariah yang pada saat jumlah dewan pengawas syariahnya berkurang tetapi kinerja bank umum syariah berdasarkan maqashid syariah indeksnya meningkat dan ada juga kolompok bank syariah pada saat jumlah dewan pengawas syariahnya berkurang tetapi kinerja bank umum syariah berdasarkan maqashid syariah indeksnya juga turun menunjukkan bahwa bertambahnya atau berkurangnya jumlah dewan pengawas syariah tidak selamanya dapat menyebabkan tinggi atau rendahnya kinerja bank umum syariah berdasarkan maqashid syariah indeks.

Ditolaknya hipotesis yang ketiga dalam penelitian ini menunjukkan bahwa dewan pengawas syariah bertanggung jawab atas lima bidang utama, yaitu: sertifikasi instrumen keuangan yang diperbolehkan melalui fatwafatwa, verifikasi kepatuhan transaksi dengan fatwa yang dikeluarkan, perhitungan dan pembayaran zakat, pencoretan pendapatan yang tidak sesuai syariah, dan saran mengenai distribusi pendapatan atau beban antara pemegang saham dan pemegang akun investasi. ${ }^{31}$ Selain itu, Dewan Pengawas Syariah merupakan salah satu unsur unik dari struktur governance bank syariah yang bertugas menghasilkan outcome yang sesuai dengan harapan stakeholder bank, yaitu terciptanya bank syariah yang patuh terhadap prinsip syariah.

Pada tataran praktis, tugas dan tanggungjawab Dewan Pengawas Syariah adalah memberikan nasihat dan saran kepada Direksi serta mengawasi kegiatan Bank agar sesuai dengan prinsip syariah. Banyaknya jumlah orang yang duduk dalam Dewan Pengawas Syariah akan memberikan pengawasan yang efektif operasinal bank syariah. Berdasarkan perspektif Islamic Accountability Theory, banyaknya jumlah orang yang duduk sebagai Dewan Pengawas Syariah akan berdampak pada efektivitas dan efesiensi pembagian tanggungjawab (division of accountability) diantara anggota Dewan Pengawas Syariah. Sehingga pertanggungjawaban syariah, sosial, dan finansial tidak hanya berada pada satu anggota tapi terdapat distribusi diantara anggota Dewan Pengawas Syariah.

Hasil penelitian ini secara koefesien regresi bernilai positif, artinya semakin banyak orang yang duduk dalam jajaran Dewan Pengawas Syariah maka semakin baik kinerja bank umum syariah berdasarkan maqashid

${ }^{31} \mathrm{H}$ Greuning, Analisis Risiko Perbankan Syariah, (Terj) Yulianti Abbas (Jakarta: Salemba Empat, 2011), 180.

Kodifikasia: Jurnal Penelitian Islam, Volume, 15 No. 1 Tahun 2021 
syariah indeks, begitupun sebaliknya. Namun, hasil penelitian ini belum mampu membuktikan jumlah dewan pengawas syariah berpengaruh secara signifikan terhadap kinerja bank umum syariah berdasarkan maqashid syariah indeks. Meskipun demikian, hasil arah koefesien atau hubungan yang positif antara jumlah dewan pengawas syariahdengan kinerja bank umum syariah berdasarkan maqashid syariah indeks relevan dengan temuan studi yang dilakukan oleh Maurya,dkk yang menganalisis hubungan antara variabel-variabel corporate governance dengan kinerja keuangan 12 bank Islam di negara-negara kawasan Teluk. Hasil penelitian menunjukkan bahwa jumlah Dewan Pengawas Syariah memiliki hubungan positif dengan kinerja keuangan perbankan yang diukur dengan ROA. ${ }^{32}$

\section{Pengaruh Jumlah Dewan Komisaris, Jumlah Komisaris Independen, dan Jumlah Dewan Pengawas Syariah terhadap Kinerja Bank Syariah Berdasarkan Maqashid Syariah Indeks}

Hasil penelitian ini mendapatkan nilai $\mathrm{F}$ hitung sebesar 4,076 > F tabel sebesar 2,79 dan nilai signifikan 0,011<0,05 maka dapat disimpulkan Ho4 ditolak dan Ha4 diterima. Artinya jumlah dewan komisaris, komisaris independen, dan dewan pengawas syariah berpengaruh signifikan terhadap kinerja bank umum syariah berdasarkan maqashid syariah indeks periode 2013-2018.

Secara parsial komisaris independen dan dewan pengawas syariah tidak berpengaruh signifikan terhadap kinerja bank umum syariah berdasarkan maqashid syariah indeks. Namun, secara simultan ketika terdapat sinergi antara jumlah dewan komisaris yang banyak, jumlah komisaris independen yang sedikit, dan jumlah dewan pengawas syariah yang banyak akan berpengaruh secara signifikan terhadap kinerja bank umum syariah berdasarkan maqashid syariah indeks. Hal ini disebabkan semakin banyak anggota dewan komisaris akan semakin mampu mengakomodasi dan memfasilitasi kepentingan setiap pihak untuk menciptakan nilai tambah bagi perusahaan. Semakin sedikit anggota komisaris independen akan semakin efektif mengurangi perilaku manajemen bertindak oportunis dan dapat meredam konflik kepentingan antara pihak prinsipal dan agen untuk lebih memperhatikan kepentingan stakeholder. Semakin banyak anggotaDPS (dewan pengawassyariah) berdampak pada efesiensi dan efektivitas division of accountability diantara anggota. Sehingga pertanggungjawaban syariah, sosial, dan finansial tidak hanya berada pada satu anggota tapi terdapat distribusi diantara anggota DPS (dewan pengawas syariah).

${ }^{32}$ Maurya et al., "Correlation Analysis between the Corporate Governance and Financial Performance of Banking Sectors Using Parameter Estimation," 27-32. 
Berpengaruhnya uji F pada penelitian ini juga dikarenakan nilai R square yaitu sebesar 0,197 yang menunjukkan bahwa jumlah dewan komisaris, jumlah komisaris independen, dan jumlah DPS (dewan pengawas syariah) mampu mempengaruhi sebesar $19,7 \%$ variasi kinerja bank umum syariah berdasarkan maqashid syariah indeks periode 2013-2018 dan sisanya sebesar $80,3 \%$ dipengaruhi oleh variabel lain di luar model penelitian ini.

\section{PENUTUP}

Berdasarkan hasil penelitian dan pembahasan tentang Islamic Corporate Governance Model Stakeholder (jumlah dewan komisaris, komisaris independen dan DPS dewan pengawas syariah) terhadap kinerja bank umum syariah di Indonesia berdasarkan maqashid syariah indeks periode 2013-2018 dapat disimpulkan bahwa berdasarkan hasil analisis regresi berganda menunjukkan bahwa jumlah dewan komisaris berpengaruh terhadap kinerja bank umum syariah di Indonesia berdasarkan maqashid syariah indeks periode 2013-2018 dengan arah positif. Jumlah dewan komisaris berpengaruh terhadap kinerja bank umum syariah berdasarkan maqashid syariah indeks karena semakin banyak anggota dewan komisaris semakin mampu mengakomodasi dan memfasilitasi kepentingan setiap stakeholder untuk mencapai maqashid syariah, yaitu: mendidik individu, menegakkan keadilan, dan memilihara kemaslahatan.

Komisaris independen tidak berpengaruh terhadap kinerja bank umum syariah di Indonesia berdasarkan maqashid syariah indeks periode 2013 2018. Jumlah komisaris independen tidak berpengaruh terhadap kinerja bank umum syariah berdasarkan maqashid syariah indeks karena adanya variasi kelompok bank umum syariah yang memiliki pergerakan data jumlah komisaris independen yang searah dan tidak searah dengan kinerja bank umum syariah berdasarkan maqashid syariah indeks, yaitu bank syariah yang pada saat jumlah komisaris independennya berkurang diiringi dengan turunnya kinerja bank umum syariah berdasarkan maqashid syariah indeks, dan bank syariah yang pada saat jumlah komisaris independennya berkurang tetapi kinerja bank umum syariah berdasarkan maqashid syariah indeksnya cenderung naik.

Jumlah dewan pengawas syariah tidak berpengaruh terhadap kinerja bank umum syariah di Indonesia berdasarkan maqashid syariah indeks periode 2013-2018. Jumlah dewan pengawas syariah tidak berpengaruh terhadap kinerja bank umum syariah berdasarkan maqashid syariah indeks karena adanya variasi kelompok bank umum syariah yang memiliki pergerakan data jumlah dewan pengawas syariah yang searah dan tidak searah dengan kinerja bank umum syariah berdasarkan maqashid syariah 
indeks, yaitu bank syariah yang pada saat jumlah dewan pengawas syariahnya berkurang diiringi dengan turunnya kinerja bank umum syariah berdasarkan maqashid syariah indeks, dan bank syariah yang pada saat jumlah dewan pengawas syariahnya berkurang tetapi kinerja bank umum syariah berdasarkan maqashid syariah indeksnya cenderung naik.

Berdasarkan hasil uji $\mathrm{F}$ menunjukkan bahwa jumlah komisaris independen tidak berpengaruh terhadap kinerja bank umum syariah berdasarkan maqashid syariah indeks periode 2013-2018. Karena terdapat sinergi yang kuat antara jumlah dewan komisaris yang banyak, jumlah komisaris independen yang sedikit, dan jumlah dewan pengawas syariah yang banyak akandapat memaksimalkan kinerja bank syariah sesuai dengan maqashid syariah yaitu mendidik individu, menegakkan keadilan, dan memelihara kemaslahatan. 


\section{DAFTAR RUJUKAN}

Abozaid, Abdulazeem, and Asyraf Wajdi Dusuki. "The Challenges of Realizing Maqasid Al-Shariah in Islamic Banking and Finance,." A Paper Presented at the IIUM International Conference on Islamic Banking and Finance:'Research and Development: The Bridge between Ideals and Realities' Organized by IIUM Institute of Islamic Banking and Finance, April 23, 2007, 1-27.

Aditiasari, Dana. "7 Hambatan Yang Buat Bank Syariah Lambat Berkembang Di RI," November 21, 2015. https://finance.detik.com/moneter/d3076959/7-hambatan-yang-buat-bank-syariah-lambat-berkembang-diri.

Badreldin, Ahmed Mohamed. "Measuring the Performance of Islamic Banks by Adapting Conventional Ratios, Working Paper Series 16." Faculty of Management Technology German University in Cairo, 2, Oktober 2009, $1-28$.

Chapra, M. Umer, and Habib Ahmed. Corporate Governance Lembaga Keuangan Syariah, (Terj) Ikhwan Abidin Basri. Jakarta: Bumi Aksara, 2008.

El-Halaby, Sherif Ismail Abdel-Rahman. "Accountability Practices of Islamic Banks: A Stakeholders' Perspective," n.d., 411.

Greuning, H. Analisis Risiko Perbankan Syariah, (Terj) Yulianti Abbas. Jakarta: Salemba Empat, 2011.

Hasan, Zulkifli. "Corporate Governance: Western and Islamic Perspecitves." International Review of Business Research Papers, 1, 5 (January 1, 2009): 277-93.

Hung, Humphry. "A Typology of the Theories of the Roles of Governing Boards." Corporate Governance: An International Review 6, no. 2 (April 1998): 101-11. https://doi.org/10.1111/1467-8683.00089.

Iqbal, Zamir, and Abbas Mirakhor. "Stakeholders Model of Governance in Islamic Economic System.” Islamic Economic Studies 11, no. 2 (n.d.): 22.

Lawal, Bello. "Board Dynamics and Corporate Performance: Review of Literature, and Empirical Challenges." International Journal of Economics and Finance 4, no. 1 (December 14, 2011): p22. https://doi.org/10.5539/ ijef.v4n1p22.

Kodifikasia: Jurnal Penelitian Islam, Volume, 15 No. 1 Tahun 2021 
Matoussi, Hamadi, and Rihab Grassa. "Is Corporate Governance Different For Islamic Banks? A Comparative Analysis Between The Gulf Cooperation Council Context And The Southeast Asia Context," n.d., 30.

Maurya, Vishwa Nath, Rama Shanker Sharma, Saad Talib Hasson Aljebori, Avadhesh Kumar Maurya, and Diwinder Kaur Arora. "Correlation Analysis between the Corporate Governance and Financial Performance of Banking Sectors Using Parameter Estimation." American Journal of Theoretical and Applied Statistics, n.d., 6.

Mohammad, Mustafa Omar, and Syahidawati Shahwan. "The Objective of Islamic Economic and Islamic Banking in Light of Maqasid Al-Shariah: A Critical Review," 2013, 10.

Mohammed, Mustafa Omar, and Dzuljastri Abdul Razak. "The Performance Measures of Islamic Bankinng Based on The Maqasid Framework," 1-17. Malaysia: Department of Economics, Kulliyyah of Economics and Management Sciences, International Islamic University Malaysia, 2008.

Mollah, Sabur, and Mahbub Zaman. "Shari'ah Supervision, Corporate Governance and Performance: Conventional vs. Islamic Banks." Journal of Banking E⿱ Finance 58 (September 2015): 418-35. https://doi. org/10.1016/j.jbankfin.2015.04.030.

Nopica, Ince, Sanep Ahmad, Abdul Ghafar Ismail, and Mohamat Sabri Hassan. "The Basic Theory of Corporate Governance in Islamic Perspective." Media Syari'ah 18, no. 2 (2016): 69-79.

Quttainah, Majdi Anwar. "Four Essays on the Impact of Shari'ah (Islamic Law) as an Institutional Governance Mechanism on Organizational Performance and Managerial Behavior," n.d., 24.

"Survei Nasional Literasi dan Inklusi Keuangan 2016." Accessed June 2, 2021. https:/www.ojk.go.id/id/berita-dan-kegiatan/siaran-pers/ Documents/Pages/Siaran-Pers-OJK-Indeks-Literasi-dan-InklusiKeuangan-Meningkat/17.01.23\%20Tayangan\%20\%20Presscon\%20 $\% 20$ nett.compressed.pdf. 